\title{
The Impact of the Academic Library on Student Success: Connecting
}

\section{the Dots}

Angie Thorpe, Ria Lukes, Diane J. Bever, and Yan He

abstract: In an age of assessment and accountability, academic libraries feel much pressure to prove their value according to new university measurements of student success. This study describes a methodology for how libraries may examine student interactions with services to assess whether library usage impacts student grade point averages (GPAs) and retention rates. Usage data were collected at six library service points during the 2013-2014 academic year. Analysis suggests an association between student use of the library and higher GPAs and retention rates. The findings may help demonstrate the value of the academic library to stakeholders and thus further integrate library services into course curricula.

\section{Introduction [A head]}

Libraries feel increasing pressure to demonstrate their value according to new university measurements of success, so their strategies for delivering evidence of their worth must evolve. Changes in student use of the library, both physically and virtually, mean that gate counts, room use counts, in-house print collection tick marks, and attendance for library instruction sessions are insufficient measures for showing student engagement with the library. Libraries must adopt the language and metrics by which other university units demonstrate their value. That is, libraries must describe the value of their services in the context of student outcomes. Two outcomes of particular interest to many higher education institutions are retention rates and grade point averages (GPAs). The hope, of course, is that students who persist in their studies and achieve higher GPAs will be more likely to complete their college degrees. For institutions that 
receive performance-based state funding, maximizing these metrics is often a key objective. It should also be a key objective for libraries.

In this study, the authors propose alternative methods—beyond head counts—by which a library can gauge student engagement with specific service points. This study replicates, to some degree, a 2011 study conducted at the University of Minnesota-Twin Cities. ${ }^{1}$ This study is unique in that it was conducted at a nonresidential, regional campus of a Midwestern public university: Indiana University (IU) Kokomo. IU Kokomo is much smaller than the University of Minnesota. The undergraduate and graduate student head count during the 2013-2014 academic year- the year of this study—was almost 2,900. ${ }^{2}$

This study offers a methodology for libraries to examine student interactions with multiple service points, including the reference desk, circulation desk, and electronic resources. A joint evaluation of service points offers librarians a more comprehensive view of how and to what extent the library is used. Libraries have been recording numbers for decades, but Joseph Matthews reminds us that, despite gate count evidence, most academic libraries have little idea of who is using their services and why. ${ }^{3}$ By combining service point usage data with demographic information, such as age range, ethnicity, and sex, the library may obtain a clearer picture of who uses which services. Most importantly, though, this study compares GPAs and retention rates for students who interacted with at least one library service point with those of the entire student body. The data reveal a correlation—although perhaps not a causality—between student use of the library and higher GPAs and retention rates. The results may help demonstrate to stakeholders outside the library, such as administrators and teaching faculty, the importance of library use on student outcomes. The findings may be used to further integrate library services into curricula in order to improve GPAs and retention rates across the institution. 


\section{Literature Review [A head]}

Professional academic library associations, including the Association of Research Libraries (ARL) and the Association of College and Research Libraries (ACRL), have recommended and used many tools and methods for assessment of library services and resources. Standardized tools include LibQUAL+ ${ }^{\circledR}$, a suite of services that allows libraries to survey users’ opinions in order to measure, understand, and take action to enhance the quality of services; ${ }^{4}$ Project SAILS, which helps librarians assess students' information literacy skills; ${ }^{5}$ and the National Survey of Student Engagement (NSSE), which collects student participation data through the College Student Report survey. ${ }^{6}$ The shortcoming of survey assessment tools, however, is that the data may be of limited utility to libraries for purposes of securing funding because, even if the data suggest that students love the library, they will probably like other areas better. ${ }^{7}$

Libraries have also adopted common business evaluation methods to measure their services. Such methods include value-added assessment, return on investment (ROI) analysis, and impact evaluation models. These strategies may be particularly appropriate in certain contexts. For example, ROI analysis shows an economic-impact or cost-benefit analysis, which libraries may use to justify budget allocations and to demonstrate value added to their institutions. Betsy Kelly, Claire Hamasu, and Barbara Jones asserted that ROI assessment can help libraries establish credibility, accountability, and evidence of value because, "Simply speaking, ROI is the right tool when talking about money."8 In describing an impact evaluation model of library assessment, Sharon Markless and David Streatfield provided a framework for library managers to identify useful impact indicators that are connected to library service 
objectives. ${ }^{9}$ This model helps libraries evaluate the effects of their services on people, rather than just how often people used the services.

Despite the variety of standardized assessment tools and evaluation methods, it is increasingly important for academic libraries to assess their impact on the outcomes that are critical to their institutions. Retention is a prominent student outcome at many higher education institutions. Several libraries have started to explore the connection between library use and student retention rates. Nicole Pagowsky and Jaime Hammond described programmatic approaches undertaken at two libraries to link library activities with institutional retention efforts. ${ }^{10}$ The rationale behind systematic integration into the curriculum and outreach initiatives is that more meaningful library interactions may help increase student engagement, and student engagement may help boost retention rates. ${ }^{11}$ This principle also guided the research of Gaby Haddow and that of Krista Soria, Jan Fransen, and Shane Nackerud. Both studies investigated associations between library usage and student enrollment and found that students who remained enrolled used library resources at much higher proportions than did students who withdrew. ${ }^{12}$ As one of the institutional systems that can contribute to student engagement, the library's role in attaining student outcomes should be evaluated. ${ }^{13}$ Even in light of compelling evidence that library use does affect student retention, Haddow cautioned that many other factors also affect whether a student stays enrolled, such as student finances and motivation levels. The results of one study may not necessarily be generalizable to all libraries everywhere. ${ }^{14}$ If the results are not generalizable, though, the methodologies may be: both research studies demonstrated the importance of connecting library use to student demographics and outcomes. Doing so helps individual libraries identify areas for improvement and offers all libraries methodologies for assessing the library's impact on retention rates. 
Although retention rates are a prevalent student outcome measurement at many higher education institutions, institutional priorities may differ, so libraries should identify the outcomes that are important at their institutions. The key is to match library assessment strategies with institutional goals. A handful of studies have sought to establish this connection by evaluating service point usage. Shane Nackerud, Jan Fransen, Kate Peterson, and Kristen Mastel evaluated the extent to which their library's services reached both undergraduate and graduate students by collecting usage data across nine service points. ${ }^{15}$ Presenting actual usage figures, rather than just anecdotal evidence, proved helpful in justifying library investments to institutional administrators. ${ }^{16}$ For the Library Impact Data Project in the United Kingdom, Graham Stone and Bryony Ramsden assessed student use of electronic resources, book loans, and library accesses against final degree attainment across eight U.K. universities. ${ }^{17}$ The results of their study, which suggested a significant association between library resource usage and degree attainment, have been used in library teaching and promotional activities. ${ }^{18}$

Libraries clearly realize that demonstrating their importance to institutional stakeholders must involve more than tallies of service point usage. Showing value must involve connecting library usage to something outside the library. Megan Oakleaf encouraged librarians to "embrac[e] an outcomes approach that reveals the impact of libraries on users." ${ }^{19}$ Libraries must define the outcomes they would like to explore and then communicate their experiences to the professional community to help develop a convincing body of evidence regarding library impact. $^{20}$

This study was modeled on the methodology used by Nackerud, Fransen, Peterson, and Mastel. It measured student interactions with six library service points and used student usernames to link usage data with demographic information, thereby connecting the dots by 
bringing together data from different places. The data allow insights into who uses library services and whether library usage affects student outcomes, namely GPAs and retention rates. Many libraries seek ways to demonstrate their value to their institutions. This methodology connects the use of multiple library service points with institutional outcomes. The results also contribute to the body of evidence demonstrating the continuing value of library services within higher education.

\section{Methodology [A head]}

Origin and Impetus [B head]

In April 2013, four librarians at IU Kokomo discussed implementing a research project and chose to emulate a 2011 library usage assessment conducted by the staff at the University of Minnesota Libraries-Twin Cities. This study analyzed institutional demographics and library use across the institution. ${ }^{21}$ At that time, except for usage counts and anecdotal feedback, the IU Kokomo Library knew little about who was using which library services. Simultaneously, the library sought deeper integrations into coursework, so a more complete understanding of current library users would allow it to reach out to academic departments more strategically. The authors sought and obtained support from the university's offices of Academic Affairs and of Information Management.

Because the research involved human subjects, the investigators submitted a successful application to the university's Institutional Review Board (IRB). An informed consent form enabled the researchers to obtain students' permission to be included in the study. The form was available in print and online formats (see Appendix A). The investigators also obtained an account to store sensitive student demographic data in Indiana University's centralized, secure Research File System. 
Service Points [B head]

The study did not seek to gather usage data from as many different library services and resources as possible. Rather, it identified the service points that should, and realistically could, be assessed by library personnel. The selected service points were:

- Questions asked at the Ask A Librarian/reference service desk, including via e-mail, telephone, chat, and in person;

- Checkout transactions at the circulation/reserves service desk for borrowed library or reserve items;

- Library instruction sessions;

- Delivery requests (student-triggered requests originating from the catalog shared by all IU libraries);

- Interlibrary loan requests (requests that could not be fulfilled through the delivery request service); and

- Log-ins on the university's proxy server, EZproxy, through which all authenticated off-campus users access online library resources.

Publicity [B head]

The investigators used graphic and textual announcements to promote the research study on the library’s homepage. Signs were also placed within the library, and the campus Media and Marketing department designed and hung a poster (see Figure 1) in the student commons. The librarians announced the study in a variety of venues, including a Faculty Senate meeting, an information technology (IT) fair, the campus student newspaper, committee meetings, and campus-wide e-mails to all faculty. Librarians also presented the study during interactions with students at service desks and during library instruction sessions. 
[Figure 1 here]

Collection of Usernames [B head]

Every IU student is assigned a unique username that he or she uses for authentication in multiple student systems, such as e-mail and the Learning Management System—-the software that distributes course content and tracks student performance. Students also need a username to log on to IU-owned computers and to access licensed electronic library resources from off-campus. The collection of usernames began on August 19, 2013 (the first day of the fall 2013 semester) and continued through May 9, 2014 (the last day of the spring 2014 semester).

The investigators collected usernames in various ways at selected service points. For instance, the library already ran monthly reports from two software products from OCLC (Online Computer Library Center): EZproxy for off-campus access and authentication; and ILLiad for resource sharing management. For services that lacked automated reports, such as library instruction sessions, library employees, including student assistants, asked students for their usernames any time they interacted with the service points. The investigators aggregated usernames across service points in a spreadsheet and then verified them through IU People, the university's online people search database. The verification was to ensure that the study only retained usernames from current IU Kokomo students.

Informed Consent [B head]

The visual announcement on the library homepage linked to an online informed consent form. All online submissions were recorded in the Qualtrics account of the principal investigator, a password-protected, institutional account for online survey software. Print consent forms were available at the Ask A Librarian/reference and circulation/reserves service desks, as well as at every library instruction session. Completed paper consent forms went into boxes on tables 
adjacent to the service desks but out of direct eyesight of the desks to give students a sense of privacy. Circulation staff and all librarians, including part-time reference librarians, received training on how to advise students of the study, describe the purpose of the consent form, and record usernames. Students were informed that the study was optional but were encouraged to participate. The consent form described additional details about how their usernames would be used to retrieve demographic details.

Retrieval of Demographic Data [B head]

When the data collection ended in May 2014, the authors completed the verification of student usernames and removed any duplicates. They submitted the complete list of usernames to the campus's institutional research analyst and received a report with the following demographic details for each username:

- Academic standing (that is, undergraduate or graduate)

- Academic level (that is, freshman, sophomore, junior, senior, or graduate)

- Academic program (for example, business, nursing, or humanities and social sciences)

- Age

- Sex

- Ethnicity

- GPA (for fall 2013 beginning, spring 2014 beginning, and spring 2014 ending)

- Enrollment status for fall 2014.

Data Analysis [B head]

The researchers tallied the number of service point interactions for each username and added these counts to the demographic report. They then culled the data for only those students who 
submitted the consent form and removed the identifying data by replacing usernames with randomly generated numeric IDs. The results that follow represent the aggregate findings from the seventy-five students who submitted consent forms. The authors used their library service point data in combination with the demographic information to analyze who used library services and whether use of library services impacted student outcomes.

\section{Results [A head]}

Student Demographics [B head]

The researchers compared the demographic characteristics of study participants with the university’s demographic student profile. Tables 1 and 2 report these comparisons. Although the study participants comprised a small group, consenting library users closely resembled the profile of all students at the university. Comparing consenting library users with the entire student population, slightly higher percentages of female, multiracial (two or more races), and Asian students used library services. A higher percentage of students aged 29 and up were also participating library users.

[TABLE 1 HERE]

\section{[TABLE 2 HERE]}

The most common academic program among responding students was the undergraduate Humanities and Social Sciences Program. Table 3 shows that 30.7 percent of respondents had declared majors in this program, which includes a variety of fields ranging from fine arts and music to criminal justice, psychology, and sociology. Participating graduate students primarily came from the Nursing Program (5.3 percent), with one additional student (1.3 percent) from the Allied Health Program. No graduate students in the Business Program took part. [TABLE 3 HERE] 
Student Outcomes [B head]

Of the students who used at least one library service and consented to participate in the study, the mean GPA for the fall 2014 term was $3.0(\mathrm{~N}=68)$. The university mean GPA was 2.5 . The mean cumulative spring 2014 GPA was also $3.0(\mathrm{~N}=57)$ for consenting library users, and the university mean was 2.9. The difference in fall 2014 term GPAs between library users and the university mean was statistically significant when a one-sample $t$-test was calculated; see figure 2. However, as seen in figure 3, the difference in spring 2014 GPAs between library users and the university mean was not statistically significant in a separate one-sample $t$-test. In statistics, a t-test examines whether a difference between two populations' averages reflects a "real” difference in the populations rather than a difference that occurred because of random chance in the sample selection. If sig (2-tailed) is less than 0.05 , the difference is considered to be statistically significant.

[FIGURE 2 HERE]

\section{[FIGURE 3 HERE]}

Retention rates may also be used as a student outcome measurement. At the end of the spring 2014 semester, 85.1 percent of participating library users who had not graduated were enrolled for the fall 2014 semester. In comparison, the retention rate for the university as a whole for the same period was 68.6 percent. A chi-square test of independence was performed to examine the statistical association between library use and retention rates. Chi-square tests are statistical tests employed to compare observed data with the results expected. They are used to determine whether significant associations exist between the variables. The larger the chi-square value, the greater the probability that a significant difference exists. The relation between library use and retention rates was significant, $\chi^{2}=609.914, p=<0.05$, and Cramer's $V=0.4089$. (Cramer's $V$ is a statistical test used to determine the strength of association after a chi-square 
test has established that there is a significant difference.) There was a weak positive association between library use and student retention, which suggests library users are somewhat more likely to persist in their studies than library nonusers.

Library Service Point Usage [B head]

Table 4 shows the frequency of library service point usage. The only evaluated service point used by a majority of the study participants was the EZproxy log-in for off-campus access to online resources. Nearly 91 percent of participants used this service, and it also received the most repeated use, with an average of 12 uses per student. The second and third most often used services both involved information literacy: Ask A Librarian/reference was utilized by 46.7 percent of respondents, and one-third of participants took part in library instruction. Both services averaged slightly more than one transaction per user, which suggests students did not visit the reference desk multiple times, nor did they likely attend more than one instruction session. The three remaining library services_checkout/renewal, interlibrary loan, and request delivery—all involve the procurement of physical library materials. Few students used these services, but the average transaction counts per user were higher than for the Ask A Librarian/reference and library instruction services.

\section{[TABLE 4 HERE]}

Of the six evaluated service points, the greatest percentage (45.7 percent) of undergraduate respondents used two services, whereas the greatest percentage (40.0 percent) of graduate respondents utilized only one service (see table 5). Approximately 1 in 4 undergraduate students used three or four library services; no undergraduates employed five or six services. Sixty percent of graduate students, however, used three, four, or five services. Again, no 
graduate students used all six services. Few students, undergraduate or graduate, seem to utilize library services to their fullest extent.

[FIGURE 4 HERE]

\section{Discussion [A head]}

Because this study emanates from observations of a small participant group, one must be cautious about generalizing the results. Even at a small institution, seventy-five participants is a low participation rate. Still, the study population resembles the university’s entire student population in many ways, and there are some intriguing findings that bear further discussion.

First, the data from this study found statistical associations between library use and student outcomes. The results suggest that students who use library services will more likely persist in their studies than those who do not use library services. The study also found a statistically significant difference between library use and higher GPAs for the fall 2013 semester but, perhaps strangely, not for the spring 2014 semester. The difference in GPAs between semesters warrants additional investigation. The next step is to evaluate whether use of specific library services is more predictive of higher GPAs and retention rates. For example, instruction may be a primary driver of better student outcomes. If more students attend instruction sessions in the fall than the spring, and students continue to have higher GPAs in the fall than the spring, this may encourage libraries to provide more instruction in the spring to potentially boost student GPAs during that time. While the data only suggest an association, not a causation, between library use and better student outcomes, they are compelling enough to encourage libraries to seek out additional strategies for integration into university activities. It is indeed a powerful argument to share with teaching faculty that even one interaction with a 
library service point may help a student stay committed to his or her coursework and continue on the path to graduation.

Use of the library alone cannot be considered the cause for participants' academic success. This study examined six service points within the library, and they do not even reflect all services provided within the library, let alone all additional services provided by the entire campus. Students interact with many units—-from admissions to financial aid to the Writing Center—during the course of a semester. Students also deal with many life issues, including work, home, and family responsibilities. To isolate a single factor as the cause for a student's success or failure is to ignore the complexity of the student experience. However, one must not discount the potential positive effect using library services may have on student outcomes. Any service that, at a minimum, demonstrates a connection between usage and improved student outcomes must be further investigated for potential wider adoption.

The study also reveals trends in student usage of library services. The most used service point was the EZproxy log-in for off-campus access to resources. Nearly 91 percent of study participants used EZproxy at least once, with the average transaction count being twelve log-ins. This high usage may be explained by several factors, such as the increasing availability of resources in electronic format, the campus' nonresidential status, large increases in asynchronous online courses, and the fact that students need not interact with any library personnel while using EZproxy. In an age where there is an ongoing transition to electronic content due to demand from college students and faculty, the high percentage of use and the large average number of transactions per user suggest the importance of promoting online resources to students and faculty. 
The remaining five service points may be grouped into two categories: services necessary to obtain materials (that is, checkout/renewal, interlibrary loan, and request delivery); and information literacy services (that is, Ask A Librarian/reference and library instruction). A greater number of students used information literacy services than materials services, but those students who used materials services tended to use them more times than did students who used information literacy services. The average transaction count for library instruction sessions (1.3) suggests there is little overlap among students who attend these sessions. The low usage of interlibrary loan and request delivery services may indicate students lack patience when it comes to obtaining library sources. Rather than searching for the best source, students may accept the information they find as satisfactory and then stop searching, perhaps because the system is difficult for them to use. ${ }^{22}$ Students may make do with items immediately available either online—via the library or not—or within the physical library, thereby contributing to less frequent use of materials request services.

Several considerations may explain the observed service point interactions. Study participants were primarily freshmen and seniors. Low usage figures for interlibrary loan and request delivery make sense among freshmen because they seldom need to use these services for their coursework. Similarly, freshmen quickly learn—either through library instruction or selfdiscovery — that they can access the library's online collection from on or off-campus, which helps account for the high frequency of EZproxy usage among study participants. The repeated use of materials services may reflect higher study participation among seniors. Ideally, by their senior year, students have become more aware of the variety of library services available to them, including services well suited for advanced research projects, such as interlibrary loan and 
request delivery. However, knowledge of services tracks back to library employees, so library employees need to be cognizant of how they teach or promote their services to students.

The service point data also reveal that few students, undergraduate or graduate, use more than three different library services. Nearly 75 percent of undergraduates utilized only one or two library services, and 60 percent of graduate students used either one or three services. Overall, only 6.7 percent of study participants, regardless of academic status, used four or more services; no participant used all six. Differences in information-seeking behaviors and informational needs may help explain why graduate students seem more likely to use additional library services: 60 percent of graduate students used three or more services compared with only 25.7 percent of undergraduates.

More than 1 in 4 (28.6 percent) undergraduate participants used only one library service. This may be attributable to the high percentage of freshmen who participated in the study; they may have lacked familiarity with or awareness of other library services. However, this fact also has implications for the library's integration into course curricula. The library needs to find additional ways to ingrain its services into coursework in order to increase use of multiple services. By understanding which library services are used and by whom, librarians can identify gaps in their student engagement practices. They can then use that information to improve or change services in order to create a more inviting, accessible library environment. Limitations [B head] A key consideration absent from this study is the role of intrinsic motivation among library users. That is, it did not evaluate whether students who participated in the study used the library because they were self-motivated or because they were required to do so. The researchers also did not request or analyze participants' high school GPAs or class rankings, so students' 
predispositions toward academic success were unknown. Finally, the investigators did not conduct pre- and post-analyses to assess whether interaction with a library service positively impacted a student's GPA, likelihood of continuing in his or her studies, or both. Future research must incorporate and attempt to address the extent to which student motivation inspires and affects library service point usage.

This study also experienced a few logistical limitations. It only assessed service points for which library employees already collected usage statistics. Within the library, use of computer workstations is monitored by University Information Technology Services staff, so this study did not assess the value of physical library spaces, at least in terms of equipment. Since many libraries are under pressure to repurpose library spaces for other departments, physical space assessment—such as computer workstation log-ins—-should be incorporated into future investigations.

This study took place at the same time that the library conducted a LibQUAL+ ${ }^{\circledR}$ survey. The small number of study participants may be partially explained by this timing: Students may have submitted one survey and then were invited to a second but thought they had already completed the survey. However, the LibQUAL+ ${ }^{\circledR}$ survey ran for only a few weeks during the spring 2014 semester, so the primary reason for the lack of participation is most likely a lack of awareness among students. This limitation may have affected EZproxy users most heavily: while library employees promoted the survey in face-to-face interactions with students, there was no such opportunity for EZproxy users, unless the student also happened to use another service. Any follow-up evaluations should incorporate more prominent and frequent marketing. Another limitation related to the EZproxy data is that usernames were only collected when students logged in to resources from off-campus. Students who conducted research on campus, therefore, 
were not included. The proxy server log-in data, then, does not accurately reflect student use of electronic resources.

Finally, the nature of this study as an IRB-approved research project necessitated the use of an informed consent form. This naturally, and rightly, limited study participants to students who expressly opted in to the investigation. Researchers interested in conducting similar projects should closely consult with their local IRBs. In some cases, when identification is removed from student data and the data are only analyzed in the aggregate, it may be possible to offer an optout consent form instead of an opt-in consent form. This would likely open up a greater quantity of usage data for libraries to analyze. Each institution has its own policies, though, and researchers must closely examine the policies to ensure that any sensitive data remain confidential.

\section{Conclusion [A head]}

As academic libraries face increasing competition for institutional funding and student attention, librarians need to employ alternative methods to gauge student engagement with and the impact of library services. While assessment is far from a new concept in libraries, assessment strategies must evolve to resonate with university administrators and stakeholders. Bruce Fraser, Charles McClure, and Emily Leahy wrote, "It is not enough simply to develop measures and to collect statistics related to library networked resources and services. ${ }^{23}$ Rather, they explained, "Academic libraries should develop a process to identify and to operationalize library outcomes that contribute to institutional outcomes." ${ }^{24}$ Usage figures, such as gate counts and head counts, are no longer sufficient to demonstrate the role of the academic library within the campus ecosystem. Rather, it is important to create a networked data collection system that is aligned with and contributes to institutional goals and thus helps demonstrate that the library is worth the 
institution's investment. The data within such a system—such as demographics and student outcome metrics-may then be shared with teaching faculty to inspire them to incorporate more library services and research assignments into their curricula.

This study collected and analyzed usage statistics from six library service points and connected the dots to find an association between student use of library services and higher GPAs and retention rates. Studies about the value of the library do not take place in a vacuum, though, which leads many to question the results library researchers reach regarding the impact of library services. These questions include what motivates students to use library services and what effects external factors, such as family life and work experiences, have on student GPAs and retention rates. These are important and valid questions, and there are undoubtedly many reasons why successful students are successful. The purpose of this study is not to say that library use is solely responsible for higher student outcomes. Instead, the intent is to present quantifiable facts demonstrating that library service engagement merits a central piece in the student success puzzle.

The next steps toward demonstrating the value of academic libraries must include presentations to stakeholders. After sharing the results of this study with upper administrators, the investigators began to work more closely with teaching faculty to integrate the use of library resources and services into course syllabi. Based on these findings, the IU Kokomo librarians plan to target additional outreach activities to the Allied Health and Business programs, since students from these areas were underrepresented in the study. The library staff also revised its strategic plan to emphasize information literacy and individualized outreach to faculty to engage with library services in deeper, more concentrated ways. 
Future studies on this topic should consider the assessment of nontraditional library "services," such as computer workstations and in-house equipment checkouts, to evaluate the value of the library as place. Analyses of study room utilization or reservations are additional options for assessing the library as place. Technology may help libraries collect data about service point usage more efficiently. Some libraries have already implemented university ID card readers to track library usage over time, and other libraries interested in investigating connections between service point usage and student outcomes may want to invest in card readers and any associated software. ${ }^{25}$ Additionally, libraries should seek to better understand the motives behind student use of library services; qualitative research strategies, including surveys or focus groups, would be beneficial toward this end.

The methodology presented in this study may serve as an initial protocol to assess the impact of the academic library. Rather than using anonymous gate counts and tally marks, collecting usernames from students who use library services allows libraries to understand who, in the aggregate, actually uses the library. By standardizing methods of collection and evaluation, libraries may compare their results with other institutions across geographic and time boundaries. Additional studies similar to the one detailed here are critical for advancing understanding among university communities of the continuing impact of the academic library on student outcomes. If multiple libraries build upon this methodology and share results across institutions, they may develop a preponderance of evidence showing that student engagement with library services plays an important role in their academic outcomes.

Angie Thorpe is the digital user experience librarian at Indiana University (IU) Kokomo; she may be reached by e-mail at: atthorpe@iuk.edu. 
Ria Lukes is the technical services librarian at IU Kokomo; her e-mail address is: rlukes@iuk.edu.

Diane J. Bever is the reference and information services librarian at IU Kokomo; she may be reached by e-mail at:dbever@iuk.edu.

Yan He is the information literacy librarian at IU Kokomo; her e-mail address is: yh4@iuk.edu.

\section{Appendix A}

\section{Indiana University Kokomo Informed Consent Form [A head]}

Study Title: Library Valuation Study 2013-2014

Study Investigator: Angie Thorpe, MLS

Introduction [B head]

You are invited to participate in a research study about student use of the Indiana University Kokomo Library, with the purpose of identifying how effective the library is in helping students achieve academic success.

Procedures [B head]

The library faculty would like to collect usernames from students who make use of the library's resources and services during the fall 2013 and spring 2014 semesters. The specific services we plan to record are circulations/loans; interlibrary loan requests; off-campus use of online library materials; library computer log-ins; library instruction sessions; and Ask A Librarian service desk usage. We will not record the specifics of your interaction with the library (e.g., which book 
you checked out, what question you asked at the Ask A Librarian service desk); only that you utilized the specified library service.

If you agree to participate, you will authorize consent for your username to be recorded and correlated with your demographic data. The demographic data that will be consulted will be: level (undergraduate or graduate; and year); school of enrollment; major; gender; ethnicity; age range; term GPA and cumulative GPA; and enrollment status for the subsequent semester.

The entire student body—approximately 3,900 students—is invited to participate in this study. Your participation will take approximately 5-10 minutes and requires submitting your username through this online Qualtrics-created consent form. No additional actions will be required of participants.

Risks/Discomforts [B head]

Risks are minimal for involvement in this study. Participants may feel emotionally uneasy about releasing their demographic data to library faculty for analysis.

Benefits [B head]

This study will benefit students by helping library faculty understand whether the library reaches the majority of students in some way or another, whether students from different schools use library materials in different ways, and whether use of the library contributes to students' academic success. The results of this study will be used to better tailor library services to actual student needs.

Confidentiality [B head]

During the collection period, all data obtained from participants will be kept confidential and only accessible to study investigators, listed below. After correlating the usage data with student 
demographic data, student usernames will be removed, and the library usage data will be analyzed in the aggregate. Students will not be personally identified for analysis purposes.

Your identity will not be revealed while the study is being conducted or when the study is reported or published. The data collected will be stored in a password-protected, HIPAA [Health Insurance Portability and Accountability Act]-aligned Research File System account within IUScholarWorks and will not be shared with any other person without your permission. Compensation [B head]

There is no direct compensation; however, participants may earn extra academic credit, at the discretion of their professors.

Participation [B head]

Your participation in this study is voluntary; you are under no obligation to participate. You have the right to withdraw at any time, or refuse to participate entirely, without jeopardy to your academic status, GPA, or standing with the university. If you choose not to participate, we will not include your username and demographic data in our data analysis.

Questions about the Research [B head]

This study and its procedures have been reviewed and approved by the IU Kokomo Institutional Review Board (IRB) for the Protection of Human Subjects. If you have questions about this study, you may contact Angie Thorpe, principal investigator, at (765) 455-9346, atthorpe@iuk.edu, IU Kokomo Library, KA140B. If you have any questions or concerns about your rights as a research participant, you may contact Dr. Shirley Aamidor, Chair IU Kokomo IRB, at (765) 455-9296, saamidor@iuk.edu, or at Indiana University Kokomo, 2300 South Washington St, PO Box 9003, Kokomo, IN 46904-9003. 
Additional study investigators are library faculty members: Diane J. Bever, (765) 455-9345, dbever@iuk.edu; Yan He, (765) 455-9249, yh4@iuk.edu; and Ria Lukes, (765) 455-9437, rlukes@iuk.edu.

I acknowledge that I have read, understood, and, if desired, printed a copy of the above consent form and desire of my own free will to participate in this study.

Yes, I agree to participate (please enter your IU Kokomo username, e.g., atthorpe, in the box below)

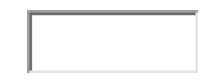

No, I decline to participate at this time Survey powered by Qualtrics.

Notes

1. Shane Nackerud, Jan Fransen, Kate Peterson, and Kristen Mastel, “Analyzing Demographics: Assessing Library Use Across the Institution,” portal: Libraries and the Academy 13, 2 (2013): 131-45, http://dx.doi.org/10.1353/pla.2013.0015; Krista M. Soria, Jan Fransen, and Shane Nackerud, “Library Use and Undergraduate Student Outcomes: New Evidence for Students’ Retention and Academic Success,” portal: Libraries and the Academy 13, 2 (2013): 147-64, http://dx.doi.org/10.1353/pla.2013.0010.

2. Indiana University Kokomo Office of Information Management, "Indiana University Kokomo: Kokomo Enrollment Summary, Fall Semester, 2013, Census,” September 6, 2013, http://iuk.edu/informationmanagement/assets/pdf/Enrollment_Overview/2013_Enrollment_Summary.pdf.

3. Joseph R. Matthews, “Assessing Library Contributions to University Outcomes: The Need for Individual Student Level Data,” Library Management 33, 6/7 (2012): 395, 
http://dx.doi.org/10.1108/01435121211266203.

4. Association of Research Libraries, “LibQUAL+ ${ }^{\circledR}, ” 2015$, http://www.libqual.org/about/about_lq/general_info.

5. Project SAILS (Standardized Assessment of Information Literacy Skills), “About Project SAILS,” 2015, https://www.projectsails.org/.

7. Eric Ackermann, "Program Assessment in Academic Libraries: An Introduction for Assessment Practitioners,” Research \& Practice in Assessment 2 (2007): 21, http://www.rpajournal.com/dev/wp-content/uploads/2012/05/A23.pdf.

8. Betsy Kelly, Claire Hamasu, and Barbara Jones, “Applying Return on Investment (ROI) in Libraries,” Journal of Library Administration 52, 8 (2012): 665, http://dx.doi.org/10.1080/01930826.2012.747383.

9. Sharon Markless and David Streatfield, Evaluating the Impact of Your Library, 2nd ed. (London: Facet Publishing, 2013), xv-xxiii.

10. Nicole Pagowsky and Jaime Hammond, “A Programmatic Approach: Systematically Tying the Library to Student Retention Efforts on Campus,” College \& Research Libraries News 73, 10 (2012): 582-94, http://crln.acrl.org/content/73/10/582.full.pdf+html.

11. Ibid., 582.

12. Gaby Haddow, “Academic Library Use and Student Retention: A Quantitative Analysis,” Library \& Information Science Research 35, 2 (2013): 131, http://dx.doi.org/ 10.1016/j.lisr.2012.12.002; Soria, Fransen, and Nackerud, “Library Use and Undergraduate Student Outcomes,” 154.

13. Haddow, “Academic Library Use and Student Retention,” 128.

14. Ibid., 133-34. 
15. Nackerud, Fransen, Peterson, and Mastel, “Analyzing Demographics,” 134-36.

16. Ibid., 143.

17. Graham Stone and Bryony Ramsden, “Library Impact Data Project: Looking for the Link between Library Usage and Student Attainment,” College \& Research Libraries 74, 6 (2013): 546-59, http://crl.acrl.org/content/74/6/546.full.pdf+html.

18. Ibid.

19. Megan Oakleaf, The Value of Academic Libraries: A Comprehensive Research Review and Report (Chicago: Association of College and Research Libraries [ACRL], 2010), 11, http://www.ala.org/acrl/sites/ala.org.acrl/files/content/issues/value/val_report.pdf.

20. Ibid., 93-94.

21. Nackerud, Fransen, Peterson, and Mastel, “Analyzing Demographics,” 133.

22. Chandra Prabha, Lynn Silipigni Connaway, Lawrence Olszewski, and Lillie R. Jenkins, "What Is Enough? Satisficing Information Needs,” Journal of Documentation 63, 1 (2007): 77, http://dx.doi.org/10.1108/00220410710723894.

23. Bruce T. Fraser, Charles R. McClure, and Emily H. Leahy, “Toward a Framework for Assessing Library and Institutional Outcomes,” portal: Libraries and the Academy 2, 4 (2002): 505.

24. Ibid., 523.

25. Mark Sanders and Chris Hodges, “An Overnight Success? Usage Patterns and Demographics of Academic Library Patrons during the Overnight Period from 11 p.m.-8 a.m.,” Journal of Access Services 11, 4 (2014): 309-20, http://dx.doi.org/10.1080/15367967.2014.945121. 